\title{
PHARMACOPHORE SCREENING AND MOLECULAR DOCKING OF PHYTOCONSTITUENTS IN POLYGONUM SAGITTATUM FOR CYCLOOXYGENASE-2 INHIBITORS DISCOVERY
}

\author{
SANDRA MEGANTARA ${ }^{1,2}$, AGUNG YODHA MW ${ }^{3}$, SAHIDIN I ${ }^{3}$, AJENG DIANTINI ${ }^{2,4}$, JUTTI LEVITA ${ }^{2,4 *}$
}

1Department of Pharmaceutical Analysis and Medicinal Chemistry, Faculty of Pharmacy, Universitas Padjadjaran, Jatinangor 45363, Indonesia. ${ }^{2}$ Scientific Consortium for Drug Discovery and Development, Universitas Padjadjaran.Indonesia. ${ }^{3}$ Department of Pharmacy, Faculty of Pharmacy, Universitas Halu Oleo, Kendari 93232, Indonesia. ${ }^{4}$ Department of Pharmacology and Clinical Pharmacy, Faculty of Pharmacy, Universitas Padjadjaran, Jatinangor 45363. Email: jutti.levita@unpad.ac.id

Received: 06 July 2017, Revised and Accepted: 29 September 2017

\section{ABSTRACT}

Objective: The objective of this study is to discover cyclooxygenase (COX-2) inhibitors from Polygonum sagittatum (Polygonaceae), by screening the pharmacophores based on the interaction of mefenamic acid with COX-2, followed by molecular docking with COX-2.

Methods: The protein crystal structure of human COX-2 in complex with mefenamic acid (PDB code: 5IKR) was selected, its ligand-protein interaction was studied by employing LigandScout to obtain the pharmacophore features. The features were validated against PGH2 database provided at http://dude.docking.org/targets/pgh2, and the result was used to screen the pharmacophores of the phytoconstituents isolated from P. sagittatum. Furthermore, a molecular docking of the phytoconstituents into COX-2 binding pocket was performed. The compounds were generated using MarvinSketch, and the energy was optimized by employing LigandScout MMFF94. Celecoxib and mefenamic acid, selective COX-2 inhibitors, were used as the standard drugs.

Results: The pharmacophore features obtained were aromatic ring (hydrophobicity) and two hydrogen bond acceptors, which are proved valid against PGH2 training set ( $\mathrm{GH}$ score $=0.78$; $\mathrm{AUC}_{100 \%}$ receiver operating characteristic curve $=0.97$ ). There are four phytoconstituents $(\mathrm{quercetin}$, protocatechuic acid, vanicoside A, and vanicoside B) that fit the features, and therefore, are predicted to be active in inhibiting COX-2. The docking reveals that three phytoconstituents (methyl-4-hydroxycinnamate, quercetin, and methyl gallate) interact with Tyr385, an important amino acid residue in COX-2 binding pocket. Quercetin is the best in inhibiting the enzyme (docking score $-8.60 \mathrm{kcal} / \mathrm{mol}$; inhibition constant $0.5 \mu \mathrm{M}$ ), compared to mefenamic acid (docking score $-8.90 \mathrm{kcal} / \mathrm{mol}$; inhibition constant $0.3 \mu \mathrm{M}$ ) and celecoxib (docking score $-10.00 \mathrm{kcal} / \mathrm{mol}$; inhibition constant $0.05 \mu \mathrm{M})$.

Conclusions: Phytoconstituents in P. sagittatum fit the pharmacophore features generated from mefenamic acid and COX-2 complex; therefore, they might be potential in inhibiting COX-2 enzyme. Their binding modes are more similar to that of mefenamic acid than of celecoxib. Of those, quercetin is the best in inhibiting the enzyme. Its inhibitory activity is equal to mefenamic acid but is weaker than celecoxib.

Keywords: Arrowleaf tearthumb, Celecoxib, Mefenamic acid, Nonsteroidal anti-inflammatory drugs, PGH2, Polygonaceae, Prostaglandin

(C) 2018 The Authors. Published by Innovare Academic Sciences Pvt Ltd. This is an open access article under the CC BY license (http://creativecommons. org/licenses/by/4. 0/) DOI: http://dx.doi.org/10.22159/ajpcr.2018.v11i1.21154

\section{INTRODUCTION}

Polygonum (Polygonaceae) that encompasses approximately 300 species are widely distributed, particularly in Asia. Information on the pharmacological effects of the genus Polygonum as well as its chemical constituents had been reviewed [1]. The previous studies indicated antinociceptive, anti-inflammatory, and diuretic properties of Polygonum barbatum [2], anticancer and radical scavenging activities of Polygonum pulchrum, Polygonum cuspidatum, and Polygonum equisetiforme [3-6], anti-HIV1 of Polygonum tinctorium and Polygonum viscosum $[7,8]$, and inhibition of tyrosinase enzyme by anthraquinones from P. cuspidatum [9].

The anti-inflammatory activity of $P$. barbatum had been evaluated in mice/rat models at the dose of $400 \mathrm{mg} / \mathrm{kg}$ body weight and resulted that the highest level of anti-inflammatory activity after $2 \mathrm{~h}$ was $39.3 \%$ inhibition on the animal's paw edema [2]. In most cases, the cause of pain is inflammatory. Nonsteroidal anti-inflammatory drugs (NSAIDs) have evolved from blocking both cyclooxygenase (COX) enzymes to selectively only inhibit COX-2 to reduce the production of inflammatory prostaglandins and thromboxanes [10]. However, due to the significant side effect of NSAIDs, recently in Indonesia, there is a greater interest in herbal medicines, which have been used empirically to reduce pain and inflammation. Many of these natural compounds also work by inhibiting COX enzymes as NSAIDs.
Resveratrol, a plant-based polyphenol molecule that is found in various concentrations of Polygonum plant, shows anti-inflammatory activity as it suppresses COX-2 by blocking NF-kB activation [11]. Many phytoconstituents had been reported in inhibiting COX-2 by interacting with Arg120 and/or Tyr355, amino acid residues located at the opening of the enzyme's catalytic site, as showed by shellegueain A (Polypodium feei) [12] and 6-gingerol (Zingiber officinale) [13]. Chalcone- and dihydrochalcone-related compounds interact with Argl20 (and/or Tyr355) and Ser530, while 4', 6, 7-trihydroxyisoflavone, quercetin, quercetin-3- methyl ether, kaempferol, and luteolin form hydrogen bond (HB) only with Ser 530. Other flavonoids that include eridicytol and myricetin form HB with Arg120. These interactions probably interfere with the formation of PGH2 in the active site of COX-1 $[14,15]$. Crystal structures of flufenamic acid, meclofenamic acid, mefenamic acid, and tolfenamic acid in complex with human COX-2 revealed that these drugs bind within the COX channel in an inverted orientation, whereas the carboxylate group interacts with Tyr-385 and Ser-530 at the top of the channel [16]. Our previous work has successfully isolated 10 phytoconstituents from Polygonum sagittatum [17]. These compounds have not been explored their pharmacological activities. This work presents the pharmacophore screening of phytoconstituents of $P$. sagittatum based on the interaction of mefenamic acid with COX-2, followed by molecular docking of the phytoconstituents with COX-2. 


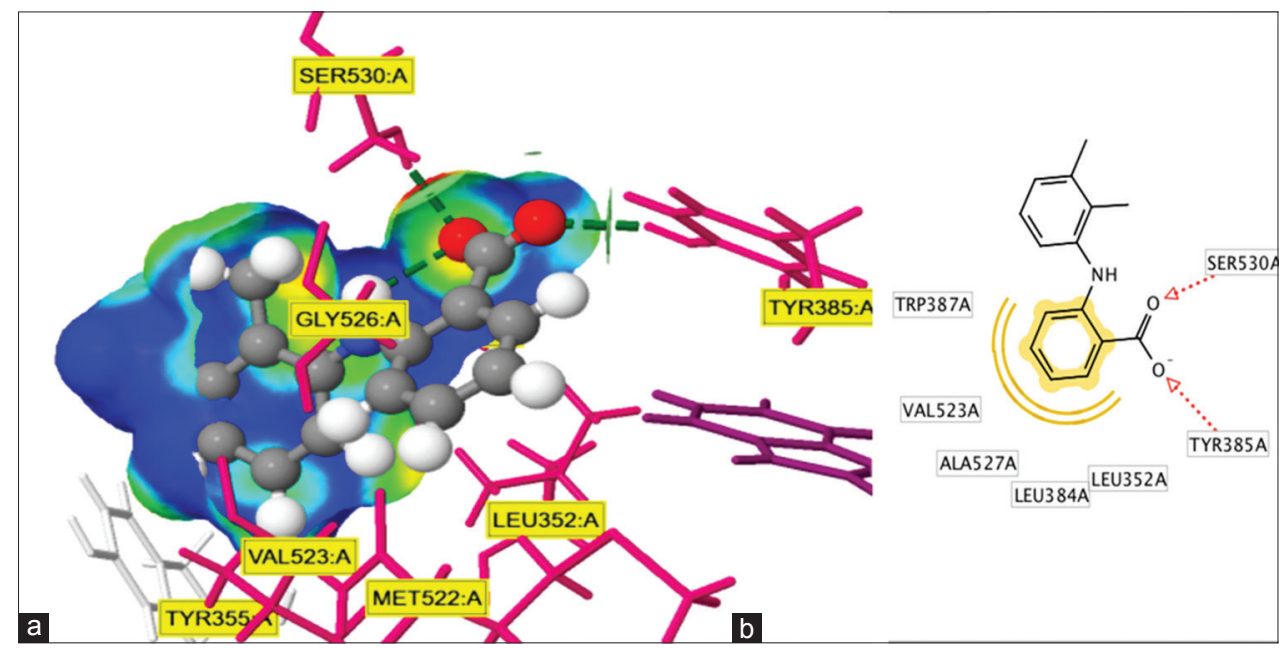

Fig. 1: (a and b) Interaction between mefenamic acid with Ser530 and Tyr385 in COX-2 catalytic site

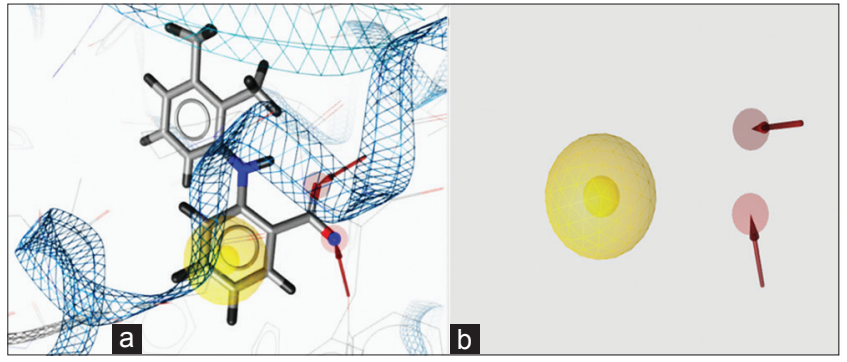

Fig. 2: (a and b) Pharmacophore features in the interaction between mefenamic acid and COX-2 created by ligand scout

\section{METHODS}

Hardware used was MacBook Pro (13-inch, Mid 2012) embedded with macOS Sierra, $2.5 \mathrm{GHz}$ Intel Core i5 processor, memory of $16 \mathrm{~GB}$ $1600 \mathrm{MHz}$ DDR3, and Intel HD Graphics $40001536 \mathrm{MB}$.

Softwares used were MarvinSketch 17.11.0 (Academic License), LigandScout 4.1.4 (Universitas Padjadjaran License), AutoDock Vina 1.1, MacPyMOL: PyMOL 1.7.4.5 Edu.

Protein preparation and validation of the pharmacophore features Protein target was the crystal structure of human COX-2 in complex with mefenamic acid (PDB code: 5IKR; resolution $2.34 \AA \AA$; R-value free 0.211), downloaded from http://www.rcsb. org/pdb/home/home.do. This protein was deposited by Orlando and Malkowski [16]. Ligandscout was employed to automatically activate the PDB interpretation algorithm and showed the complex in the Macromolecule view. Its ligand-protein interaction was studied (Fig. 1) to obtain the pharmacophore features (Fig. 2). These features were validated against PGH2 training set provided at http://dude. docking.org/targets/pgh2 by employing decoy set method. This method could be used to evaluate the discriminative ability of the best pharmacophore model and to distinguish the active compounds from the inactive compounds. A database screening was performed, and a set of statistical parameters was calculated that include the total hits (Ht), \% yield of actives, \% ratio of actives, enrichment factor (EF), false negatives, false positives, and goodness of hit score (GH), and the area under receiver operating characteristic (ROC) curve was calculated. The GH score ranges from 0 (indicates the null model) to 1 (indicates the ideal model). When the GH score exceeds 0.7 , the model is very good to identify the active compounds $[18,19]$. The result was used to screen the pharmacophores of the phytoconstituents isolated from P. sagittatum (Fig. 3).

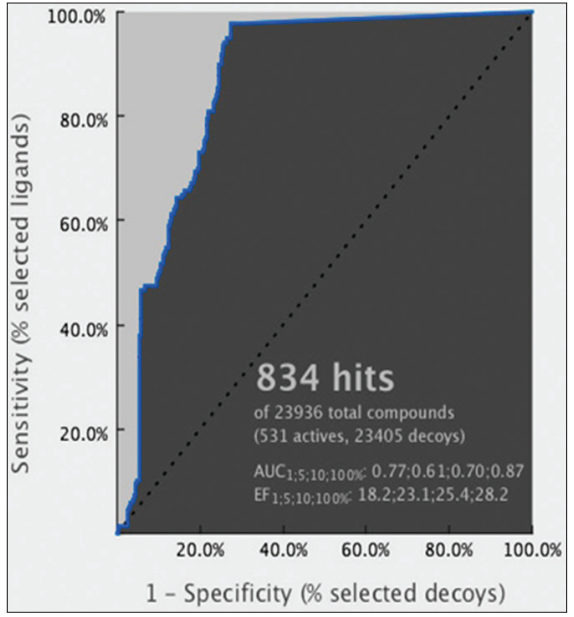

Fig. 3: Decoy set method to validate the pharmacophore features

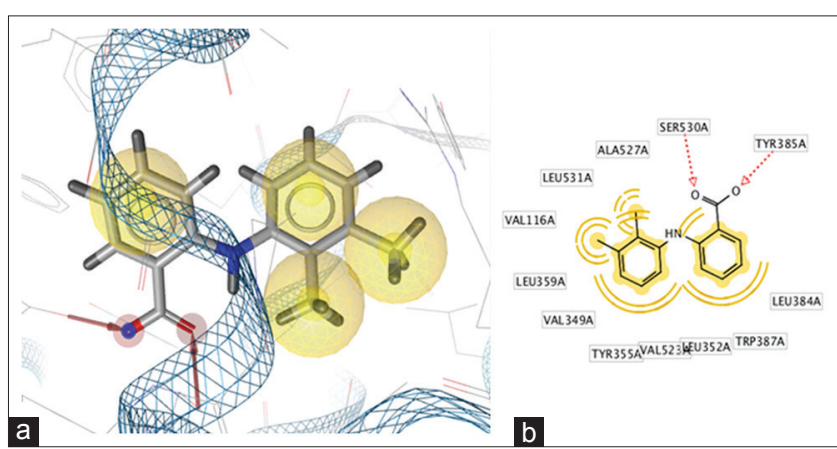

Fig. 4: Re-docking of mefenamic acid to its origin position in the catalytic site of COX-2

Validation of the docking program

To validate the docking program, the co-crystallized ligand (mefenamic acid) was separated from the protein and was re-docked into its origin position. The re-docked pose of mefenamic acid was superimposed with the origin, and the root mean square deviation (RMSD) was calculated (Fig. 4).

\section{Molecular docking}

Furthermore, a molecular docking of the phytoconstituents into COX-2 binding pocket was performed. The compounds were generated using MarvinSketch, and the energy was optimized by employing 
ligandscout MMFF94. Parameters observed were (1) the proteinligand interaction; (2) the docking score in $\mathrm{kcal} / \mathrm{mol}$; and (3) inhibition constant (Ki). Celecoxib and mefenamic acid, both selective COX-2 inhibitors, were used as the standard drugs.

\section{RESULTS AND DISCUSSION}

The crystal structure of human COX-2 in complex with mefenamic acid (PDB code: 5IKR; resolution $2.34 \AA$; R-value free 0.211 ) was selected as our protein target. The interaction between mefenamic acid and the enzyme was studied by employing JSmol and ligand scout (Fig. 1)

Fig. 1 indicated that mefenamic acid binds to Ser530 and Tyr385 in COX-2 catalytic site. Both oxygens of the acid's carboxylic group act as HB acceptors (HBAs) as shown in Fig. 1. This drug is a selective COX2 inhibitor $[16,18]$. Mefenamic acid and ibuprofen could inhibit COX-2 oxygenation of arachidonic acid [20,21].

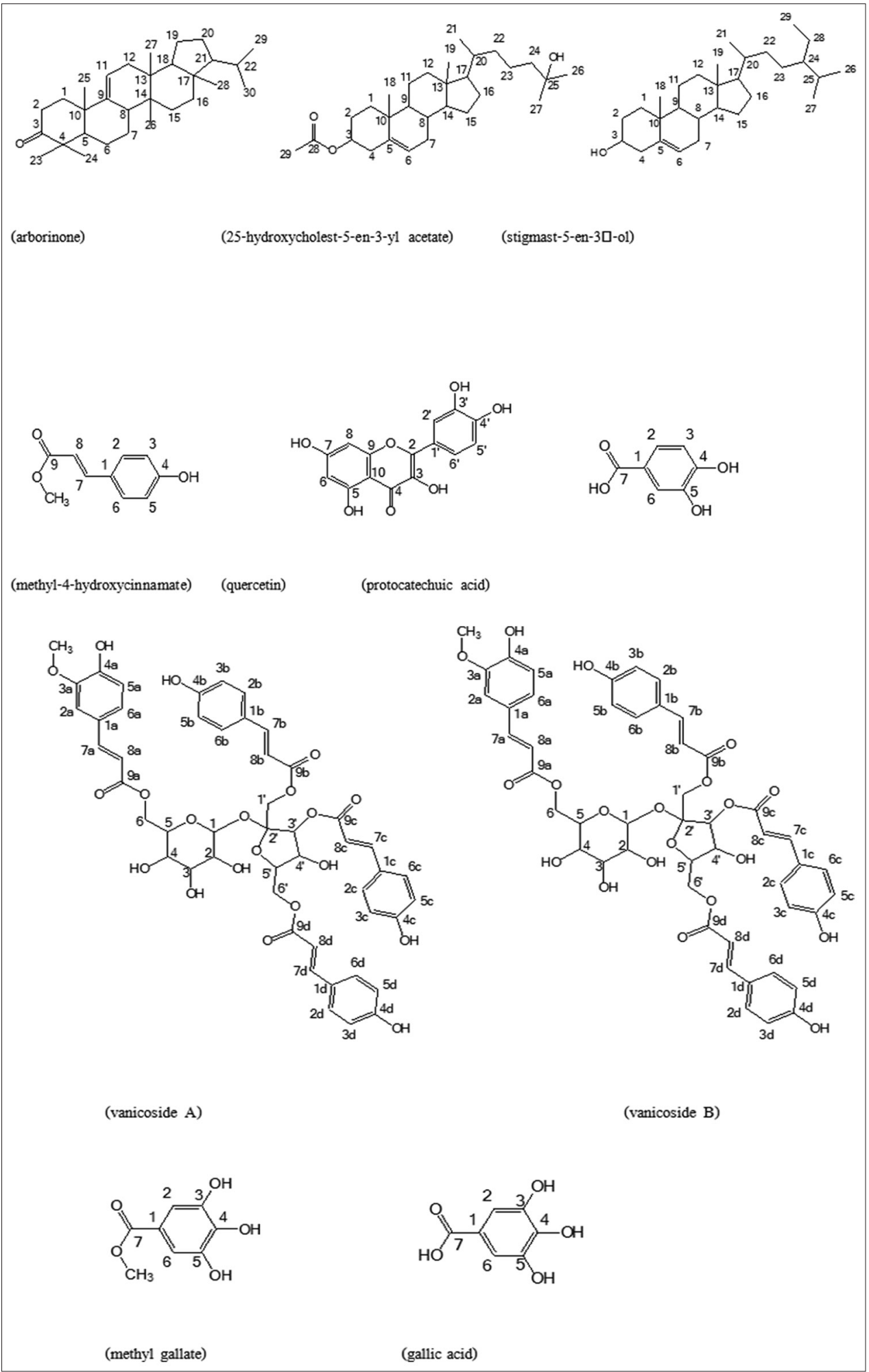

Fig. 5: Phytoconstituents isolated from Polygonum sagittatum 
Based on the interaction between mefenamic acid and COX-2, pharmacophore features were created using ligandscout and comprised 3 features: One aromatic ring (hydrophobicity) and two HBAs. These pharmacophore features are located in the important active site of COX2 (Fig. 2).

An internal database was developed using 23936 compounds containing 531 active structures collected from DUD-E (http://dude. docking.org/targets/pgh2). The validation of pharmacophore features retrieved 834 compounds, of which 522 were active against COX-2. The

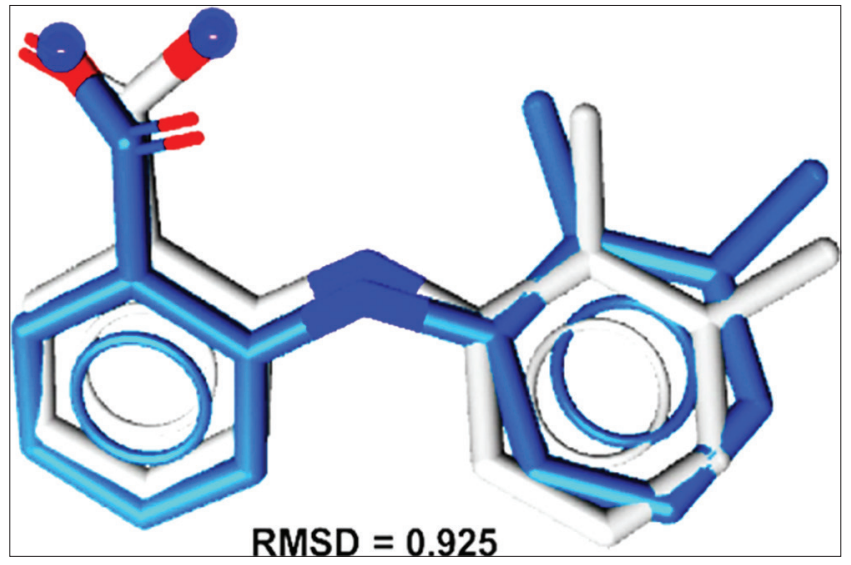

Fig. 6: Superimposition of the origin (white) and re-docked (blue) mefenamic acid molecules calculated $\mathrm{EF}=28.21$ which indicated that these features generated from mefenamic acid is highly efficient for database screening. The GH score ranges from 0 (indicates the null model) to 1 (indicates the ideal model). Our GH score $=0.71$ and AUC $_{100 \%}$ of ROC curve $=0.87$ revealed that this model could identify the active compounds and was categorized as valid (Table 1 and Fig. 3).

Ten phytoconstituents (Fig. 5) isolated from P. sagittatum [17] were generated by MarvinSketch, and their energy was minimized using LigandScout MMFF94.

Validation was performed by re-docking the co-crystallyzed mefenamic acid into its origin position in the catalytic site of COX-2 (Fig. 4). The result indicated a similar binding mode with that of the origin complex

Table 1: Statistical parameters of GH score validation

\begin{tabular}{ll}
\hline Parameter & Result \\
\hline Total compounds in PGH2 database (D) & 23936 \\
Total actives in database (A) & 531 \\
Total hits $(\mathrm{Ht})$ & 834 \\
Active hits $(\mathrm{Ha})$ & 522 \\
$\%$ yield of actives $([\mathrm{Ha} / \mathrm{Ht}] \times 100)$ & 62.59 \\
$\%$ Ratio of actives $([\mathrm{Ha} / \mathrm{A}] \times 100)$ & 98.31 \\
EF ([Ha×D]/[Ht×A]) & 28.21 \\
False negatives [A-Ha] & 9 \\
False positives [Ht-Ha] & 312 \\
Goodness of hit Score & 0.71 \\
(GH) $([\mathrm{Ha} / 4 \mathrm{HtA}][3 \mathrm{~A}+\mathrm{Ht}] \times[1-[\mathrm{Ht}-\mathrm{Ha}] /[\mathrm{D}-\mathrm{A}]])$ & \\
\hline
\end{tabular}

EF: Enrichment factor

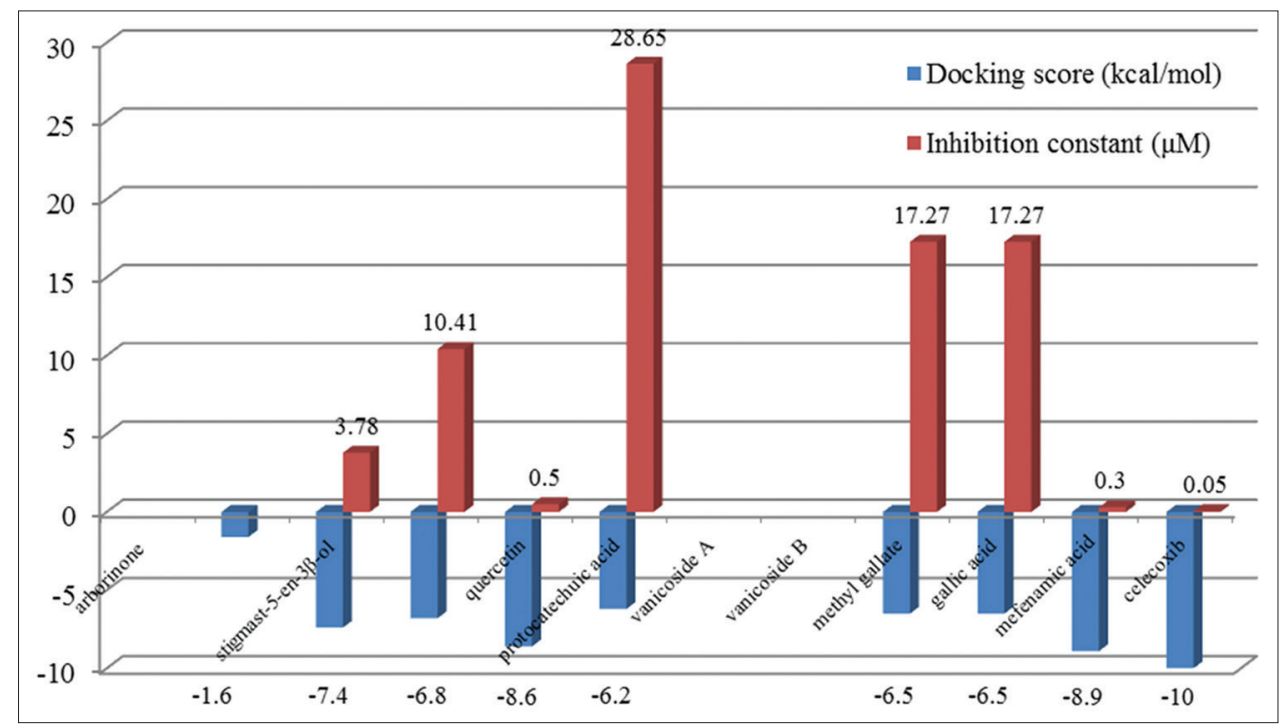

Fig. 7: Docking score and inhibition constant of the phytoconstituents of Polygonum sagittatum

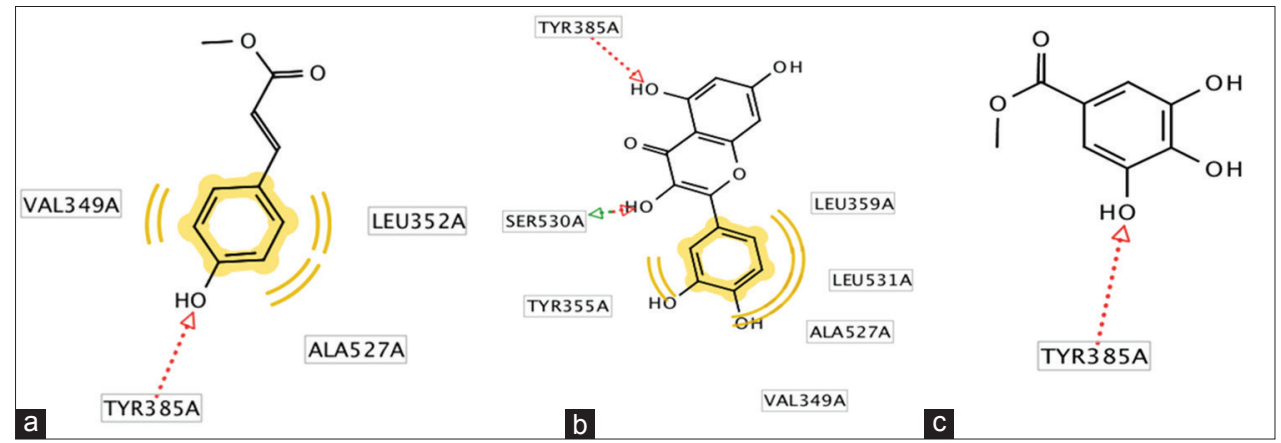

Fig. 8: Interaction of (a) methyl-4-hydroxycinnamate, (b) quercetin, and (c) methyl gallate, with Tyr385 
Table 2: Pharmacophore screening

\begin{tabular}{|c|c|c|c|}
\hline \multirow[t]{2}{*}{ Compounds } & \multicolumn{2}{|c|}{ Pharmacophore-fit score } & \multirow[t]{2}{*}{ Binding mode } \\
\hline & Hit status & Score & \\
\hline Arborinone & No & - & \\
\hline Stigmast-5-en-3 $\beta$-ol & No & - & \\
\hline Methyl-4-hydroxycinnamate & No & - & \\
\hline Quercetin & Hit & 36.77 & \\
\hline Protocatechuic acid & Hit & 38.03 & \\
\hline Vanicoside A & Hit & 36.08 & \\
\hline Vanicoside B & Hit & 36.16 & \\
\hline
\end{tabular}

(Fig. 1). Both mefenamic acid molecules interacted with Tyr385 and Ser530.

The re-docking score was $-8.90 \mathrm{kcal} / \mathrm{mol}$. The validity of the docking program was further confirmed by superimposing the re-docked pose of mefenamic acid (blue) with the origin (white), which resulted in RMSD value of 0.925 . This value is defined as valid (Fig. 6).

Pharmacophore screening of the phytoconstituents of $P$. sagittatum revealed four hits (quercetin, protocatechuic acid, vanicoside $A$, and vanicoside $\mathrm{B}$ ) that fitted the features, and therefore, these compounds were predicted to be active in inhibiting COX-2 (Table 2).

The phytoconstituents were docked into COX-2 binding pocket, and the docking score and Ki were compared to those of mefenamic acid and celecoxib (Fig. 7).

The docking revealed that three phytoconstituents (methyl-4hydroxycinnamate, quercetin, methyl gallate) interacted with Tyr385, an important amino acid residue that plays important role in producing PGH2 in COX-2 binding pocket (Fig. 8a-c)

Quercetin is the best in inhibiting the enzyme (docking score $-8.60 \mathrm{kcal} / \mathrm{mol}$; inhibition constant $0.5 \mu \mathrm{M}$ ) although its inhibitory activity is weaker compared to mefenamic acid (docking score $-8.90 \mathrm{kcal} / \mathrm{mol}$; inhibition constant $0.3 \mu \mathrm{M}$ ) and celecoxib (docking score $-10.00 \mathrm{kcal} / \mathrm{mol}$; inhibition constant $0.05 \mu \mathrm{M}$ ). Quercetin could be potential as a COX-2 inhibitor and competes with arachidonic acid in interacting with Tyr385. The binding mode of this compound (Fig. 8b) is similar to that of mefenamic acid (Fig. 1) in interacting with Tyr-385 and Ser-530 at the top of the channel. This result confirmed with the work of Kartasasmita et al. [22], which revealed that 5-OH and 7-OH moieties at the cinnamoyl ring of quercetin interacted with Gly192, Phe518, His90, and Arg513, whereas 3'-OH and 4'-OH of the benzoyl interacted with Tyr385 and Ser530.

HB formation between celecoxib, indomethacin, and diclofenac (selective inhibitors of COX-2) and Arg120 and/or Tyr355 in COX-2 are associated with the stability of the ligand-COX complex in the COX-2 pockets [23]. Moreover, recent in silico study on xanthone derivatives resulted in the HB formation of the compounds with amino acid residues Arg120, Tyr355, Tyr385, and Ser353 [24].

\section{CONCLUSIONS}

Phytoconstituents in P. sagittatum fit the pharmacophore features generated from mefenamic acid and COX-2 complex. Therefore, they might be potential in inhibiting COX-2 enzyme. Their binding modes are more similar to that of mefenamic acid than of celecoxib. Of those, quercetin is the best in inhibiting the enzyme. Its inhibitory activity is equal to mefenamic acid but is weaker than celecoxib.

\section{ACKNOWLEDGEMENT}

This work was facilitated by:

1. Scientific Consortium for Drug Discovery and Development, Universitas Padjadjaran, Indonesia

2. Academic-Leadership Grant Universitas Padjadjaran Batch-II 2017. 


\section{REFERENCES}

1. Dong X, Fu J, Yin X, Li X, Wang B, Cao S, et al. Pharmacological and other bioactivities of the genus Polygonum-a review. Trop J Pharm Res 2014;13:1749-59.

2. Mazid MA, Datta BK, Nahar L, Bashar SA, Bachar SC, Sarker SD. Antinociceptive, anti-inflammatory and diuretic properties of Polygonum barbatum (L.) Hara var. Barbata. Rev Bras Farmacogn 2009; 19:749-54.

3. Sahidin I, Suwandi A, Nohong N, Manggau MA. Profile of anticancer and radical scavenging activities of steroids from stems of Polygonum pulchrum. Int J Pharm Sci Res 2015;6(5):2178-84.

4. Kimura Y, Okuda H. Resveratrol isolated from Polygonum cuspidatum root prevents tumor growth and metastasis to lung and tumor-induced neovascularization in Lewis lung carcinoma-bearing mice. J Nutr 2001;131:1844-9.

5. Lin YW, Yang FJ, Chen CL, Lee WT, Chen RS. Free radical scavenging activity and anti-proliferative potential of Polygonum cuspidatum root extracts. J Nat Med 2010;64:146-52.

6. El-Toumy SA, Salib JY, Shafik NH, Elkarim AS, Mick GA. New flavonoids from the aerial parts of Polygonum equisetiforme SM (Polygonaceae). Int J Pharm Pharm Sci 2017;9:166-70.

7. Zhong Y, Yoshinaka Y, Takeda T, Shimizu N, Yoshizaki S, Inagaki Y, et al. Highly potent anti-HIV-1 activity isolated from fermented Polygonum tinctorium Aiton. Antiviral Res 2005;66:119-28.

8. Datta B, Datta S, Khan T, Kundu J, Rashid M, Nahar L, et al. Anticholinergic, cytotoxic and anti-HIV-1 activities of sesquiterpenes and a flavonoid glycoside from the aerial parts of Polygonum viscosum. Pharm Biol 2004;42:18-23.

9. Leu YL, Hwang TL, Hu JW, Fang JY. Anthraquinones from Polygonum cuspidatum as tyrosinase inhibitors for dermal use. Phytother Res 2008;22:552-6.

10. Maroon JC, Bost JW, Maroon A. Natural anti-inflammatory agents for pain relief. Surg Neurol Int 2010;1:80.

11. Elmali N, Baysal O, Harma A, Esenkaya I, Mizrak B. Effects of resveratrol in inflammatory arthritis. Inflammation 2007;30:1-6.

12. Hasanah AN, Levita J, Natapoera ED, Subarnas A. Analyzing the interaction of shellegueain A, a bioactive compound of Pakis tangkur (Selliguea feei or Polypodium feei) to cyclooxygenase enzyme by molecular docking. Asian J Chem 2011;23:3093-6.

13. Saptarini NM, Sitorus EY, Levita J. Structure-based in silico study of 6-gingerol, 6-shogaol, and 6-paradol, active compounds of ginger (Zingiber officinale) as COX-2 inhibitors. Int J Chem 2013;5:12-8.

14. Valdés-Barrera ID, Cuca-Suarez LE, Coy-Barrera ED. Nectandra amazonum-derived flavonoids as $\mathrm{COX}-1$ inhibitors: In vitro and docking studies. Nat Prod Commun 2014;9:649-52.

15. Dash R, Uddin MM, Hosen SM, Rahim ZB, Dinar AM, Kabir MS, et al. Molecular docking analysis of known flavonoids as duel COX-2 inhibitors in the context of cancer. Bioinformation 2015;11:543-9.

16. Orlando BJ, Malkowski MG. Substrate-selective Inhibition of cyclooxygeanse- 2 by fenamic acid derivatives is dependent on peroxide tone. J Biol Chem 2016;291:15069-81.

17. Sahidin I, Manggau MA, Widodo H. Secondary metabolites isolated from Polygonum sagittatum. Under Rev.

18. Niu MM, Qin JY, Tian CP, Yan XF, Dong FG, Cheng ZQ, et al. Tubulin inhibitors: Pharmacophore modeling, virtual screening and molecular docking. Acta Pharmacol Sin 2014;35:967-79.

19. Niu M, Dong F, Tang S, Fida G, Qin J, Qiu J, et al. Pharmacophore modeling and virtual screening for the discovery of new Type 4 camp phosphodiesterase (PDE4) inhibitors. PLoS One 2013;8:e82360.

20. Cryer B, Feldman M. Cyclooxygenase-1 and cyclooxygenase-2 selectivity of widely used nonsteroidal anti-inflammatory drugs. Am J Med 1998;104:413-21.

21. Prusakiewicz JJ, Duggan KC, Rouzer CA, Marnett LJ. Differential sensitivity and mechanism of inhibition of COX-2 oxygenation of arachidonic acid and 2-arachidonoylglycerol by ibuprofen and mefenamic acid. Biochemistry 2009;48:7353-5.

22. Kartasasmita RE, Herowati R, Harmastuti N, Gusdinar T. Quercetin derivatives docking based on study of flavonoids interaction to cyclooxygenase-2. Indo J Chem 2009;9:297-302.

23. Kumar V, Gupta GK, Kaur K, Singh R. 4-Fluorophenyl-hydrazones as potential COX-2 inhibitors: A novel, efficient, one pot solid phase synthesis, docking study and pharmacological evaluation. Med Chem Res 2013;22:5890-900

24. Miladiyah I, Jumina J, Haryana SM, Mustofa M. In silico molecular docking of xanthone derivatives as cyclooxygenase-2 inhibitor agents. Int J Pharm Pharm Sci 2017;9:98-104. 